\title{
Viljelytoimenpiteiden kannattavuuden arviointi Lohkotietopankkitietojen perusteella
}

\author{
Piia Kekkonen ${ }^{1}$, Sari Peltonen ${ }^{2}$, Pirjo Mäkelä ${ }^{3)}$ \\ 1) Maataloustieteiden laitos, Latokartanonkaari 5, 00014 Helsingin yliopisto, \\ piia.kekkonen@helsinki.fi \\ 2) \\ ProAgria Keskusten Liitto, Urheilutie 601301 Vantaa, sari.peltonen@ proagria.fi \\ 3) Maataloustieteiden laitos, Latokartanonkaari 5, 00014 Helsingin yliopisto, \\ pirjo.makela@helsinki.fi
}

Lohkotietopankki on ProAgria Keskusten Liiton ylläpitämä tietokanta, jonne on kerätty lohkokohtaista tietoa käytännön viljelmiltä vuodesta 2002 alkaen. Lohkotietopankkitiedot kattavat lohkokohtaiset viljelytiedot tehdyistä viljelytoimenpiteistä aina saavutettuun satoon ja laatuun sekä taloudellisiin tunnuslukuihin saakka viljelykasveittain. Aineisto mahdollistaa niin tilakohtaisten, alueellisten kuin valtakunnallisten vertailutietojen analysoinnin viljelyn kehittämiseksi sekä kannattavuuden ja kilpailukyvyn parantamiseksi.

Lohkotietopankista analysoitiin tietoa rehuohraviljelmiltä vuosilta 2003-2005 viljelyvyöhykkeeltä 1. Tarkastelussa olivat rehuohran keskimääräinen sato lajikkeittain sekä kasvinsuojelun vaikutus satotasoon. Lisäksi tutkimuksessa tarkasteltiin sadon vaikutusta N-, P- ja Ktaseisiin sekä taloudelliseen kannattavuuteen. Tarkastelussa olivat keskimääräisen sadon saaneet tilat (3200 kg/ha) sekä yli $4500 \mathrm{~kg} / \mathrm{ha}$ saaneet tilat.

Kasvinsuojelun vaikutus saatavaan satoon vaihteli lajikkeittain merkitsevästi. Esimerkiksi lajikkeella 'Annabell' sato oli yli $1530 \mathrm{~kg} / \mathrm{ha}$ parempi tauti- ja laontorjunnan saaneilla lohkoilla kuin käsittelemättömillä lohkoilla, kun taas lajikkeella 'Saana' sato oli $690 \mathrm{~kg} / \mathrm{ha}$ parempi tautitorjunnan saaneilla lohkoilla, mutta $70 \mathrm{~kg} / \mathrm{ha}$ alempi laontorjunnan saaneilla lohkoilla verrattuna käsittelemättömiin lohkoihin.

Satotason vaikutus N-, P-, ja K-taseisiin oli selkeä. Sadon noustessa yli $4500 \mathrm{~kg} / \mathrm{ha}$ taseluvut laskivat huomattavasti. Keskimääräisellä satotasolla $\mathrm{N}$-tase oli keskimäärin $40 \mathrm{~kg} / \mathrm{ha}$, P-tase $3 \mathrm{~kg} / \mathrm{ha}$ ja K-tase $7 \mathrm{~kg} / \mathrm{ha}$. Sadon ollessa yli $4500 \mathrm{~kg} / \mathrm{ha} \mathrm{N}$-tase oli $8 \mathrm{~kg} / \mathrm{ha}$, P-tase $-4 \mathrm{~kg} / \mathrm{ha}$ ja K - tase $-6 \mathrm{~kg} / \mathrm{ha}$. Korkean sadon saaneet tilat olivat käyttäneet typpeä lannoituksessa noin $7 \mathrm{~kg}$ enemmän kuin keskimääräisen sadon saaneet tilat. Fosfori ja kaliumlannoituksessa ei ollut merkitsevää eroa.

Satotaso vaikutti tilojen taloudelliseen tulokseen. Muuttuvat kustannukset olivat yli $4500 \mathrm{~kg}: \mathrm{n}$ hehtaarisadoilla noin 40 euroa korkeammat kuin keskimääräisen sadon tiloilla. Erot muuttuvissa kustannuksissa johtuivat erityisesti korkeammista kasvinsuojelu- ja siemenkustannuksista. Kuitenkin tarkasteltaessa katetuotto A:ta ilman tukia, taloudellinen tulos oli $3200 \mathrm{~kg} / \mathrm{ha}$ saaneilla tiloilla noin 140 euroa pienempi.

Lohkotietopankkiaineiston perusteella voidaan havaita, että hyvän satotason ja taloudellisen tuloksen saaminen edellyttää lajikeominaisuuksien tuntemista, tarpeenmukaista kasvinsuojelua sekä oikein ajoitettuja viljelytoimia. Pellon kasvukunto, sääolot sekä viljelijöiden osaaminen vaikuttavat lisäksi kasvinviljelystä saatavaan satoon, ravinnekuormitukseen sekä taloudelliseen tulokseen.

Asiasanat: Lohkotietopankki, ohra, kasvinsuojelu, ravinnetaseet, kannattavuus 


\section{Johdanto}

Viljantuotannon heikko kannattavuus ja tuottajahintojen aleneminen vähentää viljelijöiden panostusta tuotantoon ja viljelymotivaatiota. Tukipolitiikan muutokset ja markkinahintojen epävakaisuus aiheuttavat lisäksi paineita viljantuotantoon. Tuotannon suunnittelu ja viljelytoimenpiteiden kannattavuuden arviointi ovat taloudellisen tuloksen sekä ympäristölle ystävällisen lopputuloksen kannalta tärkeitä tekijöitä (Maa- ja metsätalousministeriö 10/2006).

Lohkotietopankki on ProAgria Keskusten Liiton ylläpitämä tietokanta, jonne kerätään tietoa käytännön viljelmiltä. ProAgria Keskusten Liiton ylläpitämästä tietokannasta on tallennettu tietoa eri viljelykasvien satotasoista, ravinnetaseista sekä taloudellisista tunnusluvuista. Lohkotietopankissa on kasvulohkokohtaiset tiedot viljavuusanalyysistä saaduista tuloksista ravinteiden, maan $\mathrm{pH}: n$ sekä maalajin ja maan multavuuden suhteen. Muokkaus- ja hoitotöiden ajankohdan lisäksi lohkotietopankkiaineistosta löytyvät kylvötiedot, lannoitus- ja maanparannustiedot sekä kasvinsuojelutoimet.

Ohra on Suomen yleisin viljakasvi ja sen keskimääräinen satotaso on Tilastokeskuksen mukaan $3400 \mathrm{~kg} / \mathrm{ha}$ (Tilastokeskus, 2005). Maa- ja elintarviketalouden tutkimuskeskuksen estimoitu ohran keskisatopotentiaali on noin $5000 \mathrm{~kg} / \mathrm{ha}$ (Maa- ja elintarviketalouden tutkimuskeskus, 2007). Ohran satopotentiaalia eniten rajoittavina tekijöinä pidetään ohran tautialttiutta sekä taipumusta lakoutumiseen. Taudinkestävyyden ja lakoisuuden parantaminen ovat merkittävimpiä kasvinjalostuksessa painotettavia tekijöitä (Slafer ym. 2002).

Lajikkeen, ympäristön ja viljelytoimien tuoma kokonaisuus määrittävät sadon määrän sekä tuotannon taloudellisen kannattavuuden. Taloudellisen kannattavuuden lisäksi viljelyn onnistumista voidaan mitata ravinnetaseiden avulla. Ravinnetaseiden avulla nähdään, kuinka hyvin kasvi on pystynyt käyttämään viljelyssä annettuja ravinteita kasvuunsa. Suomessa typen ravinnetase on keskimäärin $50 \mathrm{~kg} / \mathrm{ha}$ ja fosforilla $6 \mathrm{~kg} / \mathrm{ha}$ (MTT 2008).

\section{Aineisto ja menetelmät}

Tutkimuksen aineisto kerättiin ProAgria Keskusten Liiton hallinnoimasta lohkotietopankista vuosilta 2003 - 2005. Aineistoon sisältyvät lohkot, joilla on tavanomaisesti viljeltyä rehuohraa viljelyvyöhykkeellä yksi. Tutkimuksessa havainnoitiin lannoituksen määrän ja lajikeominaisuuksien vaikutusta saatavaan satoon eri kasvinsuojelumenetelmillä sekä ravinteiden sitoutumista N-, P-, ja Ktaseiden avulla. Tilastolliset analyysit tehtiin SAS tilasto-ohjelman avulla. Havainnoitavia lohkoja oli yhteensä 517 kappaletta. Havaintojen välisiä eroja mitattiin varianssianalyysin avulla.

Aineistossa havainnoidut ohralajikkeet ovat 'Annabell' , 'Scarlett', 'Saana', 'Mentor' ja 'Barke'. Ravinteiden käyttöä, ravinnetaseita sekä taloudellista kannattavuutta tarkasteltiin kahdessa eri satotason luokassa: keskimääräisen satotason tiloilla (sato $3400 \mathrm{~kg} / \mathrm{ha}$ ) sekä tiloilla, jotka kuuluvat jaottelussa satotason perusteella parhaaseen neljännekseen (sato yli $4500 \mathrm{~kg} / \mathrm{ha}$ ). 


\section{Tulokset ja tulosten tarkastelu}

Verrattaessa eri lajikkeiden keskimääräistä satotasoa yleisimmän lajikkeen 'Scarlett' satotasoon, lajikkeiden 'Annabell', 'Barke' ja 'Saana' keskimääräinen satotaso erosi lajikkeen 'Scarlett' satotasosta tilastollisesti merkitsevästi. Mikäli tauti- tai laontorjuntaa ei käytetty, lajikkeiden keskimääräinen sato erosi ainoastaan lajikkeella 'Saana'.

Eroavaisuus kasvaa saadun sadon suhteen viljelijöiden tehdessä tautitorjunta. Lajikkeella 'Annabell' keskimääräinen hehtaarisato pelkän tautitorjunnan jälkeen on keskimäärin $4800 \mathrm{~kg} / \mathrm{ha}$, kun vuorostaan lajikkeen 'Barke' satotaso on jäänyt alle 3200 kg/ha. Myös lajikkeilla 'Mentor', 'Saana' ja 'Scarlett' satotaso on noussut pelkän tautitorjunnan avulla.

Laontorjunta lisäsi keskimääräistä hehtaarisatoa kaikilla muilla lajikkeilla paitsi lajikkeella 'Saana'. Kaksitahoisista lajikkeista 'Saana' on aikaisin tarkastelussa olevista kaksitahoisista lajikkeista. Se on erittäin lujakortinen eikä tarvitse kasvunsääteitä. Sille ei kuitenkaan suositella kasvunsääteiden käyttöä, mikäli kasvustossa esiintyy kuivuusstressiä tai vastaavasti käyttömääriä suositellaan pienennettäväksi huomattavasti. Väärään ajankohtaan tehty tautitorjunta voi myös vähentää lajikkeesta saatavaa satoa (suullinen tiedonanto, Reino Aikasalo).

Suurin sadonlisä lohkotietopankkiaineiston perusteella saatiin lajikkeesta 'Scarlett'. Sen sato lisääntyi laontorjunnan avulla $\sim 950 \mathrm{~kg} / \mathrm{ha}$. Maa- ja elintarviketalouden tutkimuskeskuksen tekemissä lajikekokeissa lajikkeen 'Scarlett' satotaso on noussut kasvinsuojeluruiskutusten myötä $214 \mathrm{~kg} / \mathrm{ha}$ (Maa- ja elintarviketalouden tutkimuskeskus, 2007).

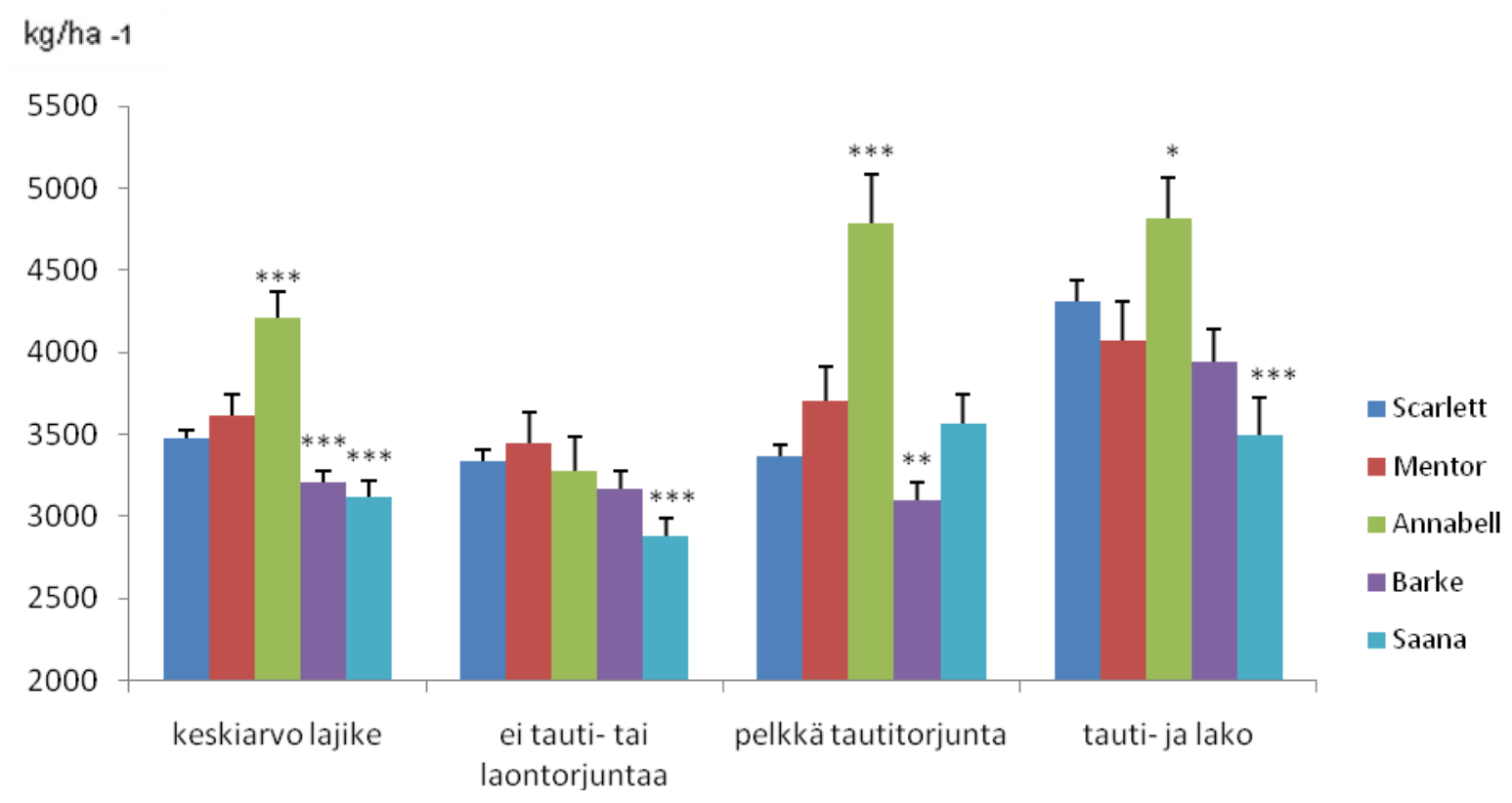

Kuva 1. Lajikkeen ja tautitorjunnan vaikutus satoon. Pylväät taulukossa kuvaavat keskivirhettä. Havainnoitavien lohkojen lukumäärät 'Scarlett' $n=275$, 'Mentor' $n=49$, 'Annabell' $n=33$ ja 'Barke' $n=220$. Tilastollisessa analyysissä vertailtavana kasvina on ohralajike 'Scarlett'.

$* \mathrm{P}<0,05$;

$* * 0,05<\mathrm{P}<0,01$

$* * * 0,01<\mathrm{P}<0,001$ 
Ohralle oli annettu typpeä keskimäärin $90 \mathrm{~kg}$ hehtaarille. Satotasoltaan parhaan neljänneksen lohkoilla, joilla satotaso oli yli $4500 \mathrm{~kg} / \mathrm{ha}$, typpeä käytettiin keskimäärin $7 \mathrm{~kg}$ enemmän. Fosforia tilat olivat käyttäneet keskimäärin $12 \mathrm{~kg} / \mathrm{ha}$ ja kaliumia keskimäärin $24 \mathrm{~kg} / \mathrm{ha}$. Lannoituksen osalta erot olivat merkitseviä ainoastaan typen osalta.

Ero ravinteiden sitoutumisessa satoon oli merkitsevä keskimääräisen satotason saaneilla tiloilla ja yli $4500 \mathrm{~kg} / \mathrm{hehtaarilta} \mathrm{saaneilla} \mathrm{tiloilla.} \mathrm{N-tase} \mathrm{oli} \mathrm{keskimääräisen} \mathrm{sadon} \mathrm{saaneilla} \mathrm{tiloilla} \mathrm{ja} \mathrm{yli} 4500$ $\mathrm{kg} /$ hehtaarilta saaneilla tiloilla. $\mathrm{N}$-tase oli keskimääräisen sadon saaneilla tiloilla $32 \mathrm{~kg} / \mathrm{ha}$ suurempi kuin tiloilla, joiden satotaso oli yli $4500 \mathrm{~kg} / \mathrm{ha}$. Myös keskimääräisen sadon saaneilla tiloilla ja hehtaarisadoltaan yli 4500 ha sadon saaneilla tiloilla fosfori- ja kaliumtaseen satoerot olivat merkitsevät.

Taulukko 1. Typpi-, fosfori-, ja kaliumtase keskiarvosatotasolla sekä yli $4500 \mathrm{~kg} / \mathrm{ha}$ sadolla.

\begin{tabular}{lrrr}
\hline & \multicolumn{1}{l}{$\begin{array}{l}\text { Sato } \\
\text { noin } 3200 \mathrm{~kg} / \mathrm{ha}\end{array}$} & \multicolumn{2}{l}{ Sato } \\
& yli $4500 \mathrm{~kg} / \mathrm{ha}$ & Erotus kg/ha \\
\hline $\mathrm{N}$ yht. kg/ha & 90 & 97 & $-7^{* *}$ \\
N-tase & 40 & 8 & $32 * * *$ \\
P yht. kg/ha & 12 & 12 & 0 \\
P-tase & 3 & -4 & $7 * * *$ \\
K yht. kg/ha & 23 & 24 & 1 \\
K-tase & 7 & -6 & $13^{* * *}$ \\
\hline$* \mathrm{P}<0,05 ;$ & & & \\
$* * 0,05<\mathrm{P}<0,01$ & & & \\
$* * * 0,01<\mathrm{P}<0,001$ & & &
\end{tabular}

Tuotantokustannukset erosivat merkitsevästi keskimääräisen satotason saaneilla tiloilla ja tiloilla, jotka yltävät parhaaseen neljännekseen. Satotasoltaan parhaassa neljänneksessä olevat tilat olivat panostaneet enemmän kylvösiemeneen sekä kasvinsuojeluun. Muuttuvat kustannukset yhteensä olivat parhaan neljänneksen tiloilla korkeammat kuin keskivertotiloilla. Katetuotto A ilman tukia on korkeamman satotason johdosta yli 4500 hehtaarisadon tiloilla parempi kuin keskivertotiloilla. Koneja lannoituskustannuksissa ei ole tilastollisesti merkitsevää eroa kahden eri satoluokan tilakokojen kohdalla.

Taulukko 2. Keskivertotilojen sekä parhaan neljänneksen tilojen taloudellinen kannattavuus. Havaintoja sato yli $4500 \mathrm{~kg} / \mathrm{ha}$ on yhteensä 51 ja keskivertotilalta 466 .

\begin{tabular}{lccc} 
& Keskivertotila & Sato yli $4500 \mathrm{~kg} / \mathrm{ha}$ & Erotus \\
\hline Sato kg/ha & 3260 & 5049 & -1789 \\
Sato €/kg & 0,11 & 0,11 & 0 \\
Kylvö & 50,8 & 66,6 & $-15,8^{* * *}$ \\
Lannoitus & 81,7 & 87 & $-5,3$ \\
Kasvinsuojelu & 31 & 44,5 & $-13,5 * * *$ \\
Muut muuttuvat kustannukset & 82,2 & 88,9 & $-6,7$ \\
Muuttuvat kulut yht. & 245,6 & 286,9 & $-41,3 * * *$ \\
Kate A it. & 117,1 & 260 & $-142,9 * * *$ \\
Konekustannukset & 231,6 & 245,3 & $-13,7$ \\
Nettovoitto/-tappio & -23 & 113 & $-136^{* * *}$ \\
& & & \\
\hline$* \mathrm{P}<0,05$ & & & \\
$* * 0,05<\mathrm{P}<0,01$ & & & \\
$* * * 0,01<\mathrm{P}<0,001$ & & &
\end{tabular}




\section{Johtopäätökset}

Tuotantoon panostaminen paransi tilojen taloudellista tulosta sekä vähensi ympäristön ravinnekuormitusta. Lohkotietopankkiaineiston perusteella keskivertomaatilat, joiden hehtaarisato oli noin $3400 \mathrm{~kg} / \mathrm{ha}$, käyttivät ravinteita viljelyyn yhtä paljon kuin tilat, jotka olivat yltäneet yli $4500 \mathrm{~kg}$ hehtaarisatoihin.

N-, P-, ja K-tase oli ylijäämäinen keskimääräisen hehtaarisadon tiloilla. Satotason noustessa yli $4500 \mathrm{~kg} / \mathrm{ha}$, ravinnetase oli ylijäämäinen pelkästään typen osalta. Yli $4500 \mathrm{~kg} / \mathrm{ha} \mathrm{P-} \mathrm{ja} \mathrm{K-tase} \mathrm{oli}$ negatiivinen. Satoero keskimääräisen satotason saaneilla tiloilla ja yli $4500 \mathrm{~kg} / \mathrm{hehtaarisadon}$ saaneilla tiloilla ei selity ravinnemäärillä.

Lohkotietopankkiaineisto antaa mahdollisuuden vertailla muun muassa tilojen välisiä viljelytoimenpiteitä sekä kustannusrakennetta. Lajikevalinta, lajikkeelle soveltuvien viljelytoimenpiteiden oikea-aikainen toteuttaminen sekä pellon kasvukunnosta huolehtiminen ovat avainasemassa tavoiteltaessa ympäristöystävällistä ja taloudellisesti kannattavaa tulosta. 


\section{Kirjallisuus}

Evans, L.T. \& Fischer, R.A. 1999. Yield Potential: Its Definition, Measurement, and Significance. Crop Sci. 39:1544-1551 (1999)

Kangas, A., Laine, A., Niskanen, M., Salo, Y., Vuorinen, M., Jauhiainen, L \& Nikander, H. 2007. Virallisten lajikekokeiden tulokset 2000 - 2007. Maa- ja elintarviketalouden tutkimuskeskus.

Tampereen Yliopistopaino Oy. s. 201.

Maa- ja metsätalousministeriö. 2006. Kansallinen viljastrategia 2006-2015. Maa- ja metsätalousministeriö 10/2006. Vammalan kirjapaino Oy.

Slafer, G.A., Molina-Cano, J.L., Savin, R., Luis Araus, J. \& Romagosa, I. 2001. Barley scienceRecent Advances from Molecular Biology to Agronomy of Field and Quality. Food Products press. New York. s. 565 